\title{
Selling Rooms Online: The Use of Social Media and Online Travel Agents
}

\section{Structured Abstract:}

\section{Purpose}

This paper focuses on the reason why hoteliers choose to be present in online travel agent (OTA) and social media websites for sales purposes. It also investigates the technological and human factors related to these two practices.

\section{Design/Methodology/Approach}

The research is based on a survey sent to a wide range of hotels in a Swiss touristic region. The empirical analysis involves the specification of two ordered logit models exploring the importance (in terms of online sales) of both social media and the online travel agent, Booking.com.

\section{Findings}

Findings highlight the constant tension between visibility and online sales in the web arena, as well as a clear distinction in social media and OTA website adoption between hospitality structures using online management tools and employing personnel with specific skills.

\section{Practical Implications}

The research highlights the need for the hospitality industry to be maintain an effective presence on social media and OTAs in order to move towards the creation of a new form of social booking technologies to increase their visibility and sales.

\section{Originality/Value}

This research contributes to understanding the major role played by OTAs and social media in the hospitality industry whilst underlining the possibility of a major interplay between the two.

Keywords: hotel technology, online travel agents, social media, online booking

Article Classification: Research Paper 


\section{Introduction}

Information and communication technologies (ICTs) have had an unprecedented impact on the hospitality sector, revolutionizing the way hotel managers' carry out day-to-day business (Law, 2009). Although hoteliers have been slow in adopting ICTs, the impact of new technologies has been acknowledged at both the marketing and selling levels (Buhalis, 2003). Academic debates on hotel websites as promotional and selling tools (e.g. Chan and Law, 2006) enlivened the research in recent years. Undoubtedly, recent developments such as the advent of social media and the rise of online travel agents (OTAs) are now challenging the industry.

The hotel website remains the core of their digital strategy (e.g. Baloglu and Pekcan, 2006) but hoteliers understand that the wise management of both social media (O'Connor, 2010) and internet distribution channels (Gazzoli et al., 2008) is a pre-requisite for success.

On the one hand, shrewd hoteliers constantly monitor OTAs, managing their presence, pricing and parity rate in order to maximize profits and occupancy (Toh et al., 2011). On the other hand, hospitality managers must engage in social media to establish a communication channel with tourists, leveraging on the good experiences of past guests and on continuous discussion (Gretzel \& Yoo, 2008). Hoteliers are realizing that managing an accommodation structure, which considers these new trends, can give them tremendous benefit with respect to competitors in terms of online sales through online channels (Filieri and McLeay, 2013).

The current study investigated the hotel sector of a touristic region of Switzerland, namely, Canton Ticino. Hoteliers were asked about the importance of social media and OTAs in their business, as well as practical questions related to the choice of OTA partner and/or the number of people employed to manage the online environment. Results describe the growing interest in social media and OTAs as means for selling rooms online.

The study starts with the next section reporting the relevant background, which is useful in highlighting the current research about the adoption of technology in hospitality, primarily focusing on social media and OTAs. The research design is then presented with the data collection details, followed by a brief descriptive analysis of the data and hypotheses for the empirical study. The last two sections focus on the results and conclusions.

\section{Literature Review}


The dramatic development of ICTs in the travel and tourism arena in the last decade (Buhalis, 2003) had an unpredictable impact on the hospitality domain (Law, 2009; O'Connor and Frew, 2002). As early as 2004, travel and tourism was recognized as the top industry in terms of the volume of online transactions (Werthner and Ricci, 2004). Within the industry, online hotel booking is the second largest sales item after air travel (in terms of revenue generated through online channels) (Marcussen, 2008). Although hoteliers have been reluctant in adopting new technologies (Buhalis, 2003; Law and Jogaratnam, 2005), the advantages resulting from ICT developments have greatly affected the hospitality domain, both in terms of marketing possibilities and sales opportunities (Schegg et al., 2013). According to Buhalis and Law (2008), the modern traveller is more conscious of the opportunities offered by the internet and therefore is more exigent. Besides, recent developments in research into online information searches (Xiang et al., 2008) has also demonstrated that travellers spend time to locate accurate information on the internet, checking different information providers (Inversini and Buhalis, 2009) before choosing the most appropriate tourism product and eventually making their online reservations (Vermeulen and Seegers, 2009).

Although reluctant to adopt new technologies (Buhalis, 2003), hoteliers have needed to acknowledge and embrace the industry shift towards technology-driven management and promotion of their facilities. Actually, in the last decade, hospitality organizations have increased their use of new technology systems as they understood that, besides concurring in reducing some operational costs (e.g. Buhalis, 2003), these tools could increase interaction with prospective guests (e.g. Chan and Guillet, 2011) for marketing and selling purposes. Consequently, technological innovations have become a prerequisite in the hospitality sector to compete and succeed in the market (Zafiropoulos et al., 2006).

For years, academics have debated the importance of hotel websites as focal points of a digital marketing and selling strategy (Phelan et al., 2011; Baloglu and Pekcan, 2006). Recently, part of the academic discussion mostly shifted onto two topics; firstly, the use of social media for engaging with prospective consumers (Filieri and McLeay, 2013), as well as the ability to influence buying behaviour (Vermeulen and Seegers, 2009) is currently being debated. Secondly, the effective use of online travel agents (OTAs - Lee et al., 2013) and general internet distribution systems (IDS - Schegg et al., 2013) has been extensively studied. The following paragraphs describe how these three relevant issues have been discussed in the literature in recent years.

Since the advent of the Internet, the topic of hotel websites had received much attention by academics and practitioners because of their possibility for triggering marketing and selling 
initiatives (Phelan et al., 2011; Buhalis, 2003). Chan and Law (2006) suggested that the hotel website has become a basic requirement for an increasing number of communication and business strategies. Particular attention was given by scholars to several research topics, such as (i) hotel website design (e.g. Rosen and Purinton, 2004), (ii) performance (e.g. Chung and Law, 2003), (iii) quality (e.g. Law and Cheung, 2006) and (iv) dimensions and attributes (e.g. Law and Hsu, 2006). Furthermore, a number of studies analysed the issue of the quality of online information on hotel websites (e.g. Chung and Law, 2003; Law and Cheung, 2006). The studies highlighted the extreme importance of content and the relevance of quality in determining a meaningful visit and a possible conversion. Chung and Law (2003) developed an information quality evaluation model for measuring the performance of hotel websites. The model is developed based on a conceptual framework comprising five major dimensions of hotel websites: (i) facility information, (ii) customer contact information, (iii) reservation information, (iv) surrounding area information and (v) website management. Law and Hsu (2006) proposed an exploratory study applying the information quality evaluation model developed in Chung and Law (2003) to enable analysis of the different perceptions of online purchasers and browsers towards specific hotel website attributes.

Furthermore, the advent of Web2.0 (e.g. O'Reilly, 2007) and social media (e.g. Haiyan, 2010) has changed the way hoteliers promote their facilities. Although the hotel website remains the focus of the online strategy (Baloglu and Pekcan, 2006), travellers also rely on different information sources available in the long tail (Buhalis and Law, 2008; Inversini and Buhalis, 2009) to support their decision process. Recent studies have cited the importance of social media (Xiang and Gretzel, 2010) as a channel for maintaining relationships with websites users and as a new marketing medium (Schmidt et al., 2008). In addition, online reviews (ORs) published both on specialized websites (e.g. TripAdvisor.com), as well as on OTA websites (e.g. booking.com), are becoming an important focus of research into marketing, eCommerce and eTourism (Filieri and McLeay, 2013). ORs' high level of credibility (Gretzel and Yoo, 2008; Fotis et al., 2012) may affect room sales (Ye et al., 2009; Vermeulen and Seegers, 2009) and act as a traveller's confidence booster, thus reducing the risk attached to booking a given accommodation (Gretzel et al., 2007). Recently, the European Travel Commission (2010) expressly recommended that hotels undertake actions to enhance online interaction with their clients. Nevertheless, even if it is demonstrated that positive comments on social media can improve consumers' attitudes towards hotels (Vermeulen and Seegers, 2009), the hospitality industry continue to struggle with incorporation of online interaction tools into their communication (Dwivedi et al., 2011). A growing number of researchers (e.g. EscobarRodríguez and Carvajal-Trujillo, 2012) view the integration between hotel online communication (i.e. hotel websites) and interactive media (i.e. social media) as a major 
development for the hospitality domain. This is because it will enable hoteliers to gain more insights on customers buying behaviour and their decision-making process (Brown et al., 2007), thereby opening new business opportunities (Hsu, 2012). Nevertheless, research on this topic is still lacking (Line and Runyan, 2012); the simple incorporation of social media within the website seems to be inadequate because social channels need particular attention in terms of strategy and management (Schmallegger and Carson, 2008; Schegg et al., 2013). Social media should be seen both as an interaction tool (i.e. checking and answering customers' reviews), according to O'Connor (2008), and a 'lead generation tool' (i.e. good comments and reviews can boost product and services sales), according to others (Ye et al., 2009; Zhu and Zhang, 2010).

Meanwhile, online distribution and booking technologies have had a great impact on the hospitality industry (O'Connor and Frew, 2002). Since 2001, online distribution has been viewed as a promise of a progressive shift from traditional reservation channels (Kasavana and Singh, 2001) to online channels, stimulating dis-intermediation (Bennett and Lai, 2005; Tse, 2003). Christodoulidou, Brewer, Feinstein and Bai (2007) identified the top five issues and challenges in online distribution for hotels, which are (i) rate control, (ii) staff education, (iii) customer loyalty, (iv) hotel website interface and (v) control of the hotel image. Another study by Gazzoli, Kim and Palakurthi (2008) highlighted the importance of consumer trust and rate parity as crucial factors of online distribution. According to TravelCLICK (2009), which runs a research based on 30 international major brands and chains, $48 \%$ of reservations were made via the internet, $27 \%$ were made from brick-and-mortar travel agents and $25 \%$ were made by voice (e.g. telephone and/or walk-ins). Only a few of the $48 \%$ reservations made via the internet were made on the hotel website, as most were actually made through OTAs. OTAs, which emerged in the 1990s (e.g. Expedia, Travelocity, Priceline), play a crucial role in online distribution. They are third-party companies that have become increasingly more powerful than hotels in terms of internet readiness (Morosan and Jeong, 2008) and economic force, putting hotels in the disadvantaged position of selling a large portion of their inventory through third-party intermediaries at heavily discounted rates (Carroll and Siguaw, 2003). Compared to hotels' websites, OTAs have the advantage of offering to consumers a one-stop-shop for book hotel rooms and even buying the entire holiday (O'Connor, 2008), mostly at a convenient price (Lee et al., 2013). Additionally, OTAs have built their success on economies of scope, aggregating products and reducing costs to provide the final consumers with cheaper solutions (Kim et al., 2009) and using data mining, direct mail, and loyalty programs, thus profiling the consumers and pushing travel products to them in different ways (Toh et al., 2011). Finally, the use of different business models (Lee et al., 2013) and smarter business practices related to pricing 
(Tso and Law, 2005; Enz, 2003) enables OTAs to provide cheaper room rates than those offered by hotel brand websites (Gazzoli et al., 2008).

Given this background and the relevance of technologies for communication and online commerce purposes, the current research provides a supply-side perspective on the importance of social media and the OTA Booking.com in terms of online sales. In particular, the potential factors influencing the perceived importance stated by hoteliers towards the two technologies are investigated by applying a quantitative approach (i.e. ordered logit class of models) for analysis of ordered categorical variables. The econometric analysis further estimates the relative impact (i.e. marginal effects) of the explanatory factors on the importance of the two technologies investigated in terms of online sales. Additionally, the current research proposes analysis of the importance of social media and OTA for sales within the same sample of hoteliers. This allows the investigation of potential differences in the way hoteliers perceive the importance of social media and OTAs (in this case, as explained below, Booking.com) as generators of online sales. Finally, based on the results obtained from the analysis performed, the current research outlines professional contributions and managerial implications for both the hospitality and OTA industries.

The research was carried out in Ticino, the Italian-speaking region of Switzerland. Switzerland is known as a forerunner country of modern tourism with a long tradition for high quality services in travel and tourism, dating back to the $19^{\text {th }}$ century. Ticino is a $2,812.2 \mathrm{~km}^{2}$ region with approximately 350,000 inhabitants (UST, 2012). The tourism sector is relatively complex with the presence of 11 local destination management organizations, 1 regional destination management organization and 2 hotel and restaurant associations, namely, Hotellerie Suisse Ticino and Gastro Ticino. The total number of hotels in the region is 511, spread within different categories. Ticino witnessed a huge touristic demand in the $1950 \mathrm{~s}$, but the trend with respect to arrivals and night stays is constantly decreasing. According to the Regional Tourism Observatory (O-Tur, 2012), Ticino had 1,058,948 arrivals in 2011 (-4.3\% with respect to 2010) and 2,372,103 night stays (-4.6\% with respect to 2010). Thus, the present research is grounded in a fertile environment where the hospitality sector is experiencing a decline while simultaneously starving for innovation.

Therefore, this research seeks to provide a twofold contribution. First, the reasons behind the adoption of social media and OTA in online sales are investigated to explain the main criteria driving the adoption of these innovations. Second, the research aims to provide insights and business recommendations for exploiting these particular media for the day-to-day activities of hoteliers. 


\section{Research Design}

\subsection{Data}

\section{Data Collection}

Starting from the above outlined literature, an online survey has been developed. Following the work of Schegg et al. (2013), the questionnaire was designed with one question concerning the distribution channels (i.e. OTAs and destination-related channels), in which hoteliers were asked to specify the monetary share required by each channel. Meanwhile, a different question asked for the share of rooms sold associated with OTAs available in the market, such as Booking.com, Expedia and HRS. Moreover, the hoteliers were asked to confirm the reasons underlying the selection of a given distribution channel according to a five-point Likert scale (from 'not at all important' to 'very important'). Further questions probed the importance of OTAs (i.e. booking.com) and UGC and social media websites (i.e. tripadvisor.com) in selling online allotments (Filieri and McLeay, 2013). Next, following a discussion on multichannel management (Kratch and Wang, 2010; Koo et al., 2011), hoteliers were asked about the management of online channels, particularly the use of channel managers (i.e. a tool for updating room availability) and the use of hotel-owned web-booking engines (i.e. integrated into the website) was investigated. Finally, hoteliers were asked about the human resources (i.e. full-time personnel) dedicated to (i) online sales management and (ii) website management (Lam et al., 2007). The final part of the survey comprises questions about star rating and the size of the hotel in terms of room numbers (Hashim et al., 2010).

The questionnaire was developed by ticinoinfo SA, the regional competence centre for technology in the tourism and hospitality sector. The questionnaire was electronically sent to the hotels in the region between June and September 2011 with the endorsement of Hotellerie Suisse Ticino and Gastro Ticino. The communication was addressed to the managing directors of the hotels (including a small proportion of bed and breakfasts, holiday homes, hostels and campsites), which were listed on the regional website, ticino.ch. Among 511 hotel questionnaires, 110 were returned (21.5\% response rate), of which 97 were usable for the following analysis. In this context, Hung and Law (2011) proposed an overview of Internetbased surveys in hospitality and tourism journals and identified the majority of the articles analysed reported response rates between $10 \%$ and $19 \%$ and between $20 \%$ and $29 \%$. Moreover, by comparing the sample descriptive statistics with official statistics, it was possible to validate the data collected according to key variables describing the hotel sector in the destination.

\section{Descriptive Analysis}


Ticino's hoteliers (Table 1 - Hotels' Specific Characteristics) are managing relatively small hotels with a mean of 43.2 rooms, but distinguishing properties with 1 room to 430 rooms, describing a highly diversified market (standard deviation=52.9), is possible. Moreover, respondents were mostly operating three-star hotels (45.0\%). Regarding the specific hotel type, $85 \%$ of the sample refers to hotels while bed and breakfasts (5\%), holiday homes $(4 \%)$, hostels (4\%) and campsites (2\%) represent the rest. According to the official statistics reported by the Regional Tourism Observatory, hotels are characterized by an average capacity of 22, 36 and 70 rooms for 0/2-star, 3-star and 4/5-star hotels, respectively (O-Tur, 2012). The average capacity for the hotels represented in the sample amounts to 21, 39 and 67 rooms for 0/2-star, 3-star and 4/5-star hotels, respectively, supporting the validity of the data.

When dealing with bookings, $79.4 \%$ of the reservations are made online or are internetmediated (e.g. OTA, email, booking on the hotel website and so on), whereas only $20.6 \%$ are carried out using traditional channels (walk-ins, fax, letter, telephone and so on). Among OTAs, the most popular platform is Booking.com; $51.2 \%$ of the interviewed hoteliers utilize this platform to engage with the online market, paying an average commission of $10.9 \%$. Commission rate does not seem to be among the most important issues for hoteliers in choosing to allocate rooms on a given OTA website. Hoteliers focus more on the popularity and importance of the platform as well as the marketing effectiveness and resource of the platform itself (Table 1 - Importance of Specific Factors in Selection of an Online Platform).

When asked about the importance in terms of sales, hoteliers indicated Booking.com as the most important among OTAs (51.2\% of the respondents ranked it as the most important online platform) and rated it as an important channel for generating online sales (Table 1 - Importance for Online Sales). Nonetheless, social media are also popular and somewhat important (note the small SD) in driving sales within the sample.

Finally, when asked about the management of the 'online domain', responses were quite surprising. Barely half (53.0\%) of the hoteliers interviewed had a booking engine on the hotel website and less than one in three $(28.0 \%)$ used a channel manager to update the different sales channels (Table 1 - Online Management). With regard to the full-time personnel dedicated to the management of the 'online domain', $70.0 \%$ of the hoteliers have at least one part-time employee taking care of the website, whereas $78.0 \%$ have at least one part-time employee dedicated to online sales management. (Table 1 - Full Time Personnel Dedicated to)

[INSERT TABLE 1]

\subsection{Method}


The empirical analysis involves the specification of two ordered logit models reflecting on two main research objectives, namely (i) the importance of social media in terms of online sales and (ii) the importance of OTAs (particularly booking.com) in terms of online sales. The importance of social media and OTAs is also tested against online management styles (Schegg et al., 2013) and adoption factors (Lam et al., 2007; Hashim et al., 2010). Particularly, three sets of hypotheses have been formulated and successively tested through model estimation.

The first set of hypotheses ( $\mathrm{H} 1$ and $\mathrm{H} 2)$ regards the relationship between social media and OTAs and online sales (Filieri and McLeay, 2013; Gazzoli et al., 2008). On the one side, literature suggests that social media are playing a crucial role in fostering online bookings for hotels (Ye et al., 2009); online reviews have been proven to be influential in selling products also outside the tourism domain (e.g. Chevalier and Mayzlin, 2003; Zhu and Zhang, 2006). Actually, social media are not only enabling two-way communication between firms and customers (Gretzel et al., 2007) but they are also playing a crucial role in influencing c'nsumers' buying behaviour (Vermeulen and Seegers, 2009). On the other side, OTAs are playing a key role within the hospitality sector (Kim et al., 2009) and online distribution channels have gradually become a common way to make travel arrangements (Law et al., 2007). Moreover, the hospitality field is witnessing massive use of OTAs, both by travellers (e.g. to find the premium price - Lee et al., 2013) and by hoteliers (i.e. to dis-intermediate - Tse, 2003). Thus, to investigate the relationship between the importance of social media and Booking.com (the most used OTA in the sample - please refer to table 1), the following two hypotheses are formulated:

H.1a: The importance of social media for online sales is influenced by the importance hoteliers perceive about Booking.com.

H.1b: The importance of Booking.com for online sales is influenced by the importance hoteliers perceive about social media.

For the specific factors influencing the importance of either social media (Gretzel and Yoo, 2008) or Booking.com for online sales, additional hypotheses are formulated based on possible factors affecting the adoption of a given OTA portal, such as commission (Toh et al., 2011) and the importance and popularity of the online platform (Schegg et al., 2013):

H.2a: The importance of social media for online sales is influenced by the importance of specific factors hoteliers consider when selecting an OTA.

H.2b: The importance of Booking.com for online sales is influenced by the importance of specific factors hoteliers consider when selecting an OTA. 
The second set of hypotheses, regard the management styles of hoteliers (H3). According to Kracht and Wang (2010), the advances of ICT have not reduced the number of "middle men" in the hospitality distribution funnel but rather resulted in an increasingly complex array of intermediaries (Kracht and Wang, 2010). This is leading to so-called multichannel management (Neslin and Shankar, 2009), a practice that allows hoteliers to provide products/contingencies on various internet-based reservation channels trying to facilitate the encounter with the potential consumers (Koo, Mantin and O'Connor, 2011). Recent research has defined different online management styles (e.g. Schegg et al., 2013), focusing on the technology adopted by hoteliers for this purpose (e.g. channel managers). H3 considers as a key factors for determining the level of online management, (i) the use of a channel manager and (ii) the integration of booking engines on hotel websites (e.g. Cantoni et al., 2011).

H.3a: The importance of social media for online sales is influenced by the online management implemented by the hotel

H.3b: The importance of Booking.com for online sales is influenced by the online management implemented by the hotel

The last set of hypotheses (H4 and H5) investigates the relationship among technology adoption factors and the use of social media and the given OTA. Recent studies (e.g. Wang and Qualls, 2007) have demonstrated that the technology adoption process in the hospitality field may encounter two different kind of challenges. The first is human factor barriers, which include both employees and managers related issues (e.g. Hasan, 2003; Lam et al., 2007; Lee and Miller, 1999; Thompson and Richardson, 1996), whilst the second is hotel characteristics, such as size, star rating and affiliation (e.g. Hashim et al., 2010; Murphy et al., 2006; Orfila-Sintes, Crespí-Cladera and Martínez-Ros, 2005). Therefore, the H4 hypotheses are related to human resources actually dedicated to the management of the technologies.

H.4a: The importance of social media for online sales is influenced by the personnel dedicated to website and online sales management.

H.4b: The importance of Booking.com for online sales is influenced by the personnel dedicated to website and online sales management.

Hypotheses H5 are related to hotels characteristics (Chevalier and Mayzlin, 2003) that may influence the use of social media and OTA.

H.5a: The importance of social media for online sales is influenced by hotel-specific characteristics. 
H.5b: The importance of Booking.com for online sales is influenced by hotel-specific characteristics.

According to the categorical ordered nature of the dependent variables underlying the two sets of hypotheses, namely the importance of social media and Booking.com for online sales, the ordered logit class of models is considered for the estimation. Indeed, the use of traditional statistical methods, such as the linear regression, would fail to recognize the ranking nature of the discrete dependent variable (Greene, 2003), leading to bias in estimates. In particular, the ordered logit model is specified as follows:

$$
y_{i}^{*}=\sum_{k} \beta_{k} x_{i k}+\varepsilon_{i}
$$

where $\beta_{k}$ are the coefficients associated with the independent variables $x_{k}$. The dependent variable $y^{*}$ is expressed as an unobserved continuous latent variable, linked to the five observed discrete ordered outcomes $\left(y_{j}\right)$, considered in the present survey, as follows:

$$
\begin{aligned}
& y=0 \text { if } y^{*} \leq 0, \\
& y=1 \text { if } 0<y^{*} \leq \mu_{1}, \\
& y=2 \text { if } \mu_{1}<y^{*} \leq \mu_{2}, \\
& y=3 \text { if } \mu_{2}<y^{*} \leq \mu_{3}, \\
& y=4 \text { if } y^{*}>\mu_{3},
\end{aligned}
$$

where the threshold parameters $\mu_{s}$ are unknown and estimated within the specified model. The error term $\varepsilon$ is assumed to follow a standard logistic distribution. In this context, the probability that respondent $i$ selected outcome $j$, given the observed variables $x_{i}$, is calculated as follows:

$$
\operatorname{prob}\left(y_{i}=j \mid x_{i}\right)=\left[\Lambda\left(\mu_{j}-\beta^{\prime} x_{i}\right)-\Lambda\left(\mu_{j-1}-\beta^{\prime} x_{i}\right)\right]>0,
$$

where $\Lambda$ (.) indicates the cumulative distribution function of the logistical distribution.

The estimation of coefficients $\beta_{k}$ and threshold parameters $\mu_{s}$ relies on maximization of the following likelihood function:

$$
\begin{aligned}
\ln L(\beta, \mu \mid y, x) & =\sum_{i} \sum_{j} \operatorname{prob}\left(y_{i}=j \mid x_{i}\right) \\
& =\sum_{i} \sum_{j} \ln \left[\Lambda\left(\mu_{j}-\beta^{\prime} x_{i}\right)-\Lambda\left(\mu_{j-1}-\beta^{\prime} x_{i}\right)\right] .
\end{aligned}
$$

To boost the interpretation of the coefficients estimated in the models, the related marginal effects are further derived as follows: 


$$
\frac{\partial \operatorname{prob}\left(y_{i}=j \mid x_{i}\right)}{\partial x_{i}}=\left[\Lambda\left(\mu_{j-1}-\beta^{\prime} x_{i}\right)-\Lambda\left(\mu_{j}-\beta^{\prime} x_{i}\right)\right] \times \beta
$$

For model specification, the methodology applied follows backward selection; therefore, only the significant variables appear in the final model. The estimation of the model for the importance of Booking.com is performed on the full set of data, whereas the model for the importance of social media relies on a subset of 92 observations due to a total of five missing values in two of the independent variables used.

\section{Results}

Two ordered logit models have been estimated to investigate the hypotheses within the two research questions formulated in the previous sections. The model results are reported in Table 5. The first column refers to the model estimated on the importance of social media (model 'SocialMedia') for online sales, whereas the model estimating the importance of Booking.com for online sales is reported in the second column (model 'Booking.com'). The bottom part of the table indicates the estimates for the threshold parameters and the model fits, the latter is represented in terms of log-likelihood function at the initial point where only the constant is included $\left(\ln L_{\text {Restricted }}\right)$ and at convergence $\left(\ln L_{\text {Model }}\right)$, McFadden pseudo $R^{2}$ (calculated as: $1-\frac{\ln L_{\text {Model }}}{\ln L_{\text {Restricted }}}$ ), Count $R^{2}$ (calculated as: $\frac{N_{\text {Correct predictions }}}{N_{\text {Tot }}}$ ) and Adjusted Count $R^{2}$ (calculated as: $\frac{N_{\text {Correct predictions }}-N_{\text {Most frequent outcome }}}{N_{\text {Tot }}-N_{\text {Most frequent outcome }}}$.

The log-likelihood function at convergence consistently increases for both models supporting the validity of the explicative variables used in the model specifications, as confirmed by the McFadden pseudo $R^{2}$. Furthermore, the measure Count $R^{2}$ indicates that $50 \%$ of the predictions are correctly estimated by model 'SocialMedia' ( $65 \%$ by model 'Booking.com'). The threshold parameter results are all significantly different from zero. In this context, we note that for model 'Booking.com', the outcomes 'not at all important' and 'not important' have been appropriately merged due to the statistically insignificant difference between the two related threshold parameters (leading to the estimation of only two threshold parameters).

Looking at the estimates across the two models, a significant and positive relationship between the importance of Booking.com and the importance of social media for online sales is observed, which is confirmed by both models estimated because the two variables enter both models (either as dependent or independent variables). This result supports hypothesis H.1 (i.e. hypothesis H1a and H1b), indicating a direct relationship between the importance of OTAs and social media being perceived by hoteliers in terms of online sales. 


\section{[INSERT TABLE 2]}

An interesting analysis involves the comparison of influential factors across the two models, estimated in order to investigate potential differences in the way hoteliers perceive the importance of social media and OTA Booking.com in terms of online sales. In this context, the estimates obtained for each single model suggest a differentiated pattern for the significant factors influencing the two variables under investigation. In particular, for model 'SocialMedia', only two of the aspects driving the selection of an online platform turned out to be significant. Specifically, a positive relationship is observed between the importance of social media for online sales and the importance associated with both the functionality of booking technology and the effectiveness of marketing and resources of an online platform. Although this result supports hypothesis H.2a only marginally, it represents an interesting finding. Indeed, innovative forms of booking technology, together with effective marketing, can facilitate the link between OTAs and social media. Conversely, for model 'Booking.com', four significant aspects driving the selection of an online platform and influencing the importance of Booking.com for online sales are evident, suggesting partial support of hypothesis H.2b. In particular, the more hoteliers evaluate aspects such as 'popularity' and 'importance of the platform' as important, the more Booking.com is rated as important for online sales. Conversely, a negative relationship is observed between the importance of Booking.com and the importance of the aspects 'effectiveness of marketing and resources' and 'commission'. Hence, although these two aspects are considered important in the selection of a generic online platform, they are negatively associated with the specific importance of online sales generated by the platform Booking.com. Particularly interesting is the negative effect observed for the importance of commission, suggesting, from a hotelier perspective, the willingness to give up part of the marginal profit in exchange for gaining a larger overall volume of bookings (or overall revenue) expected by the use of a popular and important online travel agency platform.

Focusing on hotel online management and personnel, we find that the presence of an integrated booking engine in the hotel website increases the likelihood to rate social media as an important tool for online sales. This finding is indeed coherent with the expectation because the implementation of a booking engine can enhance the dynamic characteristics of social media. We can therefore support hypothesis H.3a, while rejecting hypothesis H.3b, because no significant impacts are evident between hotel online management and the importance of Booking.com for online sales. In terms of full-time personnel, a substantial duality captured by the estimates obtained across the two models is observed. For the model 'Booking.com', a significant and positive impact is associated with the personnel dedicated to online sales management, whereas for the model 'SocialMedia', a significant and positive impact is verified 
in relation to the personnel dedicated to website management. A counter effect for the model 'SocialMedia' is further associated with the personnel dedicated to online sales management. These findings reflect the different tasks (and efforts) underlying the two managerial roles, providing proof of the robustness of the models proposed and, hence, supporting both hypotheses H.4a and H.4b.

Interestingly, with regard to hotel-specific characteristics, the importance of social media for online sales is positively influenced (at an alpha level of $0.15 \%$ ) by hotel room capacity, whereas the hotel category affects the perceived importance of Booking.com. In particular, considering that the coefficients associated with hotel categories are normalized with respect to the lower category (i.e. zero to two stars), a higher likelihood to rate Booking.com is observed to be important for hoteliers belonging to the three-star category, whereas the four- to five-star category does not show any significant difference compared to the normalized category. This result suggests a different underlying perception of hoteliers towards the two online technologies, in which social media seems to be related to hotel capacity (e.g. an effective instrument for increasing the occupancy rate as much as possible). Conversely, the use of the online platform Booking.com seems rather demand-driven (e.g. an instrument particularly effective for certain quality categories, such as three-star hotels). Hence, both hypotheses H.5a and H.5b are supported by our analysis.

To gain a better understanding of the relative impact of the significant variables obtained for the two models presented in Table 2, the corresponding marginal effects are further calculated and proposed in Table 3. Table 3 reports the change in the probability of the outcome 'very important' (yj=4) associated with a unit change (of the mean value) of the independent variables (xi).

\section{[TABLE 3]}

Regarding the marginal effects obtained from the model 'SocialMedia', we note that a unit increase in the importance of Booking.com increases the probability to rate social media as 'very important' for online sales by $10.2 \%$. Between the two significant aspects in the selection of an online platform, a stronger effect is found for the functionality of booking technology (compared to the effectiveness of marketing and resources). This is providing that a unit increase in its importance results in a $8.3 \%$ increase in the probability of rating social media as 'very important' (compared to a 5.8\% increase associated with the effectiveness of marketing and resources). Furthermore, the presence of a booking engine in the hotel website consistently increases the probability of perceiving social media as 'very important' by $20.1 \%$. Interestingly, an additional person dedicated to website management increases the probability of 
social media to be 'very important' by $7.0 \%$, against a $13.2 \%$ decrease of the same probability if the additional person is dedicated to online sales management. A smaller impact is associated with an increase in room capacity, in which 10 additional rooms would bring a $1 \%$ increase of the social media being evaluated as 'very important'.

Focusing on the marginal effects derived from model 'Booking.com', larger magnitudes of the effects are observed if compared to those obtained from model 'SocialMedia'. In particular, a unit increase in the importance of social media results in a $21.4 \%$ increase in the probability to evaluate Booking.com as 'very important'. Among the factors influencing the selection of an online platform, the largest marginal effect is associated with the popularity of the platform itself, indicating a $20.4 \%$ increase in the probability to rate Booking.com as 'very important' as a result of a unit increase in the importance of the online platform's popularity. In contrast, a unit increase in the importance of the 'effectiveness of marketing and resources' in the selection of an online platform decreases the probability to rate Booking.com as 'very important' for online sales by $16.9 \%$. In terms of dedicated personnel, a $19.3 \%$ increase is observed in the probability of Booking.com being perceived as 'very important' for each additional person dedicated to hotel online sales management. Finally, the consistent effect underlying the hotel categories is noted, in which hoteliers belonging to the three-star category show a $33.4 \%$ higher probability to rate Booking.com as 'very important' compared to hoteliers belonging to other categories, which are zero to two stars and four to five stars, respectively.

\section{Discussion and Conclusions}

Academic contributions and practical implications for the industry can be drawn from the above-presented analysis.

Firstly, despite the ever-growing literature in this field, no studies have yet concentrated on analysis of the combined social media and OTA effects on online sales specifically focusing on (i) online platform choice criteria, (ii) online sales channels management, (iii) human resources involvement and (iv) hotels characteristics. The quantitative approach (i.e. ordered logit class of models) used in the study represents a rigorous method for analysis of ordered categorical variables, allowing for appropriate estimation of the factors influencing the importance of both social media and OTA for online sales and the associated marginal effects. In particular, this research highlights the fact that, in terms of importance for online sales, hoteliers perceived a direct relationship between OTAs and social media, where the latter has a stronger effect on the importance of OTAs than OTAs have on the importance of social media. The probability of perceiving social media and OTAs important for online sales further varies according to several other factors, which, interestingly, are different across the two variables investigated. For the 
importance of social media, we noted the centrality of (i) the presence of booking engine technologies on the hotel website, (ii) personnel dedicated to website management and (iii) room capacity. For the importance of the OTA Booking.com, relevant factors include (i) the popularity of online channels, (ii) personnel dedicated to online sales management and (iii) hotel category.

Secondly, it is noted that innovative forms of booking technology, together with effective marketing, could facilitate the link between OTAs and social media. Thus, three different conclusions with practical implications have been drawn.

(i) The interplay between OTAs and social media reflects the tension (and in some respect, the dilemma) between visibility and revenue, leading to the possibility of creating new distribution strategies.

Active social media presence and the presence on OTA portals are essential factors for modern hoteliers who, on the one hand need to engage with former and prospective clients to raise awareness of and interest in their property and, on the other hand, need to find a convenient commercial outlet for their property. A particularly interesting aspect of this last issue is the negative effect observed for the importance of commission, which suggests, from a hotelier perspective, the willingness to lose part of the marginal profit in exchange for gaining a larger overall volume of bookings (or overall revenue) expected by the use of a popular and important online travel agency platform. This result highlights a tension between visibility and sales volume, suggesting the possibility of envisaging more sophisticated distribution systems based on the peculiar characteristics of social media (to increase the visibility), rather than on those of OTAs (to increase sales volume). Thus, it would be possible to tackle directly the issue of disintermediation in the near future by leveraging on social media communication and exposure (e.g. real-time booking, experience customization) to sell rooms online.

(ii) The implementation of hotel-owned software to sell and manage online distribution influences the interest of hoteliers in the use of social media.

Particularly, the use of a hotel-owned booking engine increases the likelihood to rate the social media as an important tool for online sales. This finding is indeed coherent with the expectation because the implementation of selling technologies within the accommodation environment can enhance the dynamic characteristics and predisposition of hoteliers towards social media. The more the hotelier is inclined to adopt technological solutions to enter the online competitive arena, the higher the likelihood of exploiting the possibilities of leveraging on social media communication and using it as a proper selling channel. Hoteliers need to enter the online arena 
taking care of online sales as well as online communication and marketing. A professional, coherent and consistent presence both on online selling channels and online discussion channels (i.e. social media) will foster online sales.

(iii) The centrality of the human factor and the related different competencies needed is crucial for the hospitality industry to operate in OTAs and social media.

With regard to hotel online management and personnel, the human factor emerged as a key issue for hoteliers. Being effectively active, both in social media and in OTAs, implies having personnel with different skills and training needs. A counter effect for the model 'SocialMedia' is further associated with the personnel dedicated to online sales management. These findings reflect the different tasks (and efforts) underlying the two managerial roles, providing proof of the robustness of the models proposed and, hence, supporting both hypotheses H.4a and H.4b. In particular, considering the coefficients associated with hotel categories are normalized with respect to the lower category (i.e. zero to two stars), a higher likelihood to rate Booking.com is observed to be important for hoteliers belonging to the three-star category, whereas the four- to five-star category does not show any significant difference compared to the normalized category. This result suggests a different underlying perception of hoteliers towards the two online technologies, in which social media seem to be related to hotel capacity (e.g. an effective instrument for increasing the occupancy rate as much as possible). Conversely, the use of the online platform Booking.com seems rather demand-driven (e.g. an instrument particularly effective for certain quality categories, such as three-star hotels). Finally, while the current research suggests that hoteliers show a different perception toward the factors influencing the importance of social media and OTA for online sales, the results obtained are confined to the destination under study. Further research in different geographical and touristic contexts is encouraged in order to support the findings and provide a wider generalizability of the results.

\section{References}

Baloglu, S. \& Pekcan, Y. A. (2006). The website design and Internet site marketing practices of upscale and luxury hotels in Turkey. Tourism Management, 27(1), 171-176.

Bennett, M. M. \& Lai, C.-W. K. (2005). The Impact of the Internet on Travel Agencies in Taiwan. Tourism and Hospitality Research, 6(1), 8-23.

Brown, J., Broderick, A. J. \& Lee, N. (2007). Word of mouth communication within online communities: Conceptualizing the online social network. Journal of Interactive Marketing, $21(3), 2-20$.

Buhalis, D. (2003). ETourism : information technology for strategic tourism management. Harlow, England: Financial Times Prentice Hall. 
Buhalis, D. \& Law, R. (2008). Progress in information technology and tourism management: 20 years on and 10 years after the Internet-The state of eTourism research. Tourism Management, 29(4), 609-623.

Carroll, B. \& Siguaw, J. (2003). The evolution of electronic distribution: Effects on hotels and intermediaries. The Cornell Hotel and Restaurant Administration Quarterly, 44(4), 38-50.

Chan, N. L. \& Guillet, B. D. (2011). Investigation of Social Media Marketing: How Does the Hotel Industry in Hong Kong Perform in Marketing on Social Media Websites? Journal of Travel \& Tourism Marketing, 28(4), 345-368.

Chan, S. \& Law, R. (2006). Automatic Website Evaluations: The Case of Hotels in Hong Kong. Information Technology \& Tourism, 8(3-4), 255-269.

Chevalier, J. A. \& Mayzlin, D. (2003). The Effect of Word of Mouth on Sales: Online Book Reviews (Working Paper No. 10148). National Bureau of Economic Research. Retrieved from http://www.nber.org/papers/w10148

Christodoulidou, N., Brewer, P., Feinstein, A. H. \& Bai, B. (2007). Electronic channels of distribution: challenges and solutions for hotel operators. FIU Hospitality and Tourism Review, 25(2), 92-100.

Chung, T. \& Law, R. (2003). Developing a performance indicator for hotel websites. International Journal of Hospitality Management, 22(1), 119-125.

Enz, C. A. (2003). Hotel pricing in a networked world. The Cornell Hotel and Restaurant Administration Quarterly, 44(1), 4-5.

Escobar-Rodríguez, T. \& Carvajal-Trujillo, E. (2012). An evaluation of Spanish hotel websites: Informational vs. relational strategies. International Journal of Hospitality Management, (33), 228-239.

European Travel Commission. (2010). World Usage Patterns \& Demographics. ETC - New Media Trend Watch. Retrieved March 2, 2013, from http://www.newmediatrendwatch.com/world-overview/34-world-usage-patterns-anddemographics

Filieri, R. \& McLeay, F. (2013). E-WOM and Accommodation: An Analysis of the Factors That Influence Travelers' Adoption of Information from Online Reviews. Journal of Travel Research. doi: 10.1177/0047287513481274

Fotis, J., Buhalis, D. \& Rossides, N. (2012). Publications. In M. Fuchs, F. Ricci \& L. Cantoni (Eds.), Information and Communication Technologies in Tourism 2012 (pp. 13-24). Vienna, Austria.

Gazzoli, G., Kim, W. G. \& Palakurthi, R. (2008). Online distribution strategies and competition: are the global hotel companies getting it right? International Journal of Contemporary Hospitality Management, 20(4), 375-387.

Greene, W. H. (2003). Econometric Analysis (5th ed.). Pearson Education. 
Gretzel, U, Yoo, K. H. \& Purifoy, M. (2007). Online travel review study: role and impact of online travel reviews. Texas A \& M University. Department of Recreation, Park and Tourism Sciences. Laboratory for Intelligent Systems in Tourism. Retrieved from http://www.tripadvisor.com/pdfs/OnlineTravelReviewReport.pdf

Gretzel, U. \& Yoo, K. H. (2008). Use and Impact of Online Travel Reviews. In D. P. O'Connor, D. W. Höpken \& D. U. Gretzel (Eds.), Information and Communication Technologies in Tourism 2008 (pp. 35-46). Springer Vienna.

Haiyan, C. (2010). An Impact of Social Media on Online Travel Information Search in China. In 2010 International Conference on Information Management, Innovation Management and Industrial Engineering (ICIII) (Vol. 3, pp. 509 -512). Presented at the 2010 International Conference on Information Management, Innovation Management and Industrial Engineering (ICIII).

Hasan, B. (2003). The influence of specific computer experiences on computer self-efficacy beliefs. Computers in Human Behavior, 19(4), 443-450.

Hashim, N. H., Murphy, J., Purchase, S. \& O’Connor, P. (2010). Website and email adoption by Malaysian hotels. International Journal of Hospitality Management, 29(1), 194-196.

Hsu, Y.-L. (2012). Facebook as international eMarketing strategy of Taiwan hotels. International Journal of Hospitality Management, 31(3), 972-980.

Hung, K. \& Law, R. (2011). An overview of Internet-based surveys in hospitality and tourism journals. Tourism Management, 32(4), 717-724.

Inversini, A. \& Buhalis, D. (2009). Information Convergence in the Long Tail: The Case of Tourism Destination Information. In W. Höpken, U. Gretzel \& R. Law (Eds.), Information and Communication Technologies in Tourism 2009 (pp. 381-392). Vienna: Springer Vienna.

Kasavana, M. L. \& Singh, A. J. (2001). Online Auctions. Journal of Hospitality \& Leisure Marketing, 9(3-4), 127-140.

Kim, J., Bojanic, D. C. \& Warnick, R. B. (2009). Price Bundling and Travel Product Pricing Practices Used by Online Channels of Distribution. Journal of Travel Research, 47(4), 403412.

Koo, B., Mantin, B. \& O'Connor, P. (2011). Online distribution of airline tickets: Should airlines adopt a single or a multi-channel approach? Tourism Management, 32(1), 69-74.

Kracht, J. \& Wang, Y. (2010). Examining the tourism distribution channel: evolution and transformation. International Journal of Contemporary Hospitality Management, 22(5), 736757.

Lam, T., Cho, V. \& Qu, H. (2007). A study of hotel employee behavioral intentions towards adoption of information technology. International Journal of Hospitality Management, 26(1), $49-65$. 
Law, R. (2009). Disintermediation of hotel reservations: The perception of different groups of online buyers in Hong Kong. International Journal of Contemporary Hospitality Management, 21(6), 766-772.

Law, R., Chan, I. \& Goh, C. (2007). Where to find the lowest hotel room rates on the internet? The case of Hong Kong. International Journal of Contemporary Hospitality Management, 19(6), 495-506.

Law, R. \& Cheung, C. (2006). A study of the perceived importance of the overall website quality of different classes of hotels. International Journal of Hospitality Management, 25(3), $525-531$.

Law, R. \& Hsu, C. H. C. (2006). Importance of Hotel Website Dimensions and Attributes: Perceptions of Online Browsers and Online Purchasers. Journal of Hospitality \& Tourism Research, 30(3), 295-312.

Law, R. \& Jogaratnam, G. (2005). A study of hotel information technology applications. International Journal of Contemporary Hospitality Management, 17(2), 170-180.

Lee, H., Guillet, B. D. \& Law, R. (2013). An Examination of the Relationship between Online Travel Agents and Hotels A Case Study of Choice Hotels International and Expedia.com. Cornell Hospitality Quarterly, 54(1), 95-107.

Lee, J. \& Miller, D. (1999). People matter: commitment to employees, strategy and performance in Korean firms. Strategic Management Journal, 20(6), 579-593.

Line, N. D. \& Runyan, R. C. (2012). Hospitality marketing research: Recent trends and future directions. International Journal of Hospitality Management, 31(2), 477-488.

Marcussen, C. H. (2008). Trends in European internet distribution - of travel and tourism services. Trends in European internet distribution - of travel and tourism services. Retrieved February 2, 2013, from http://195.130.87.21:8080/dspace/handle/123456789/864

Morosan, C. \& Jeong, M. (2008). Users' perceptions of two types of hotel reservation Web sites. International Journal of Hospitality Management, 27(2), 284-292.

Mridula Dwivedi, Anil Yadav \& Umashankar Venkatesh. (2011). Use of social media by national tourism organizations: a preliminary analysis. Information Technology and Tourism, 13(2), 93-103.

Murphy, J., Schegg, R. \& Olaru, D. (2006). Investigating the Evolution of Hotel Internet Adoption. Information Technology \& Tourism, 8(3-4), 161-177.

Neslin, S. A. \& Shankar, V. (2009). Key Issues in Multichannel Customer Management: Current Knowledge and Future Directions. Journal of Interactive Marketing, 23(1), 70-81.

O-Tur. (2012). Statistica sulla domanda di turismo in Ticino. Ossrvatorio Sul Turismo Ticinese. Retrieved February 2, 2012, from http://www.otur.usi.ch/sites/www.otur.usi.ch/files/uploads/otur_domanda_dicembre_2011.pdf 
O'Connor, P. (2008). User-Generated Content and Travel: A Case Study on Tripadvisor.Com. In D. P. O'Connor, D. W. Höpken \& D. U. Gretzel (Eds.), Information and Communication Technologies in Tourism 2008 (pp. 47-58). Springer Vienna.

O'Connor, P. \& Frew, A. J. (2002). The future of hotel electronic distribution: expert and industry perspectives. Cornell Hotel and Restaurant Administration Quarterly, 43(3), 33-45.

O’Connor, P. (2008). Electronic Distribution (Vol. Handbook of Hospitality Operations and IT). Routledge.

O'Connor, P. (2010). Managing a Hotel's Image on TripAdvisor. Journal of Hospitality Marketing \& Management, 19(7), 754-772.

O'Reilly, T. (2007). What is Web 2.0: Design Patterns and Business Models for the Next Generation of Software (SSRN Scholarly Paper No. ID 1008839). Rochester, NY: Social Science Research Network. Retrieved from http://papers.ssrn.com/abstract=1008839

Orfila-Sintes, F., Crespí-Cladera, R. \& Martínez-Ros, E. (2005). Innovation activity in the hotel industry: Evidence from Balearic Islands. Tourism Management, 26(6), 851-865.

Phelan, K. V., Christodoulidou, N., Countryman, C. C. \& Kistner, L. J. (2011). To book or not to book: the role of hotel web site heuristics. Journal of Services Marketing, 25(2), 134-148.

Rosen, D. E. \& Purinton, E. (2004). Website design: Viewing the web as a cognitive landscape. Journal of Business Research, 57(7), 787-794.

Schegg, R., Stangl, B., Fux, M. \& Inversini, A. (2013). Distribution Channels and Management in the Swiss Hotel Sector. In $n g, Z$., Proocedings of Information and Communication Technologies in Tourism 2013 (pp. 554-565). Presented at the ENTER2013, Innsbruck: Springer.

Schmallegger, D. \& Carson, D. (2008). Blogs in tourism: Changing approaches to information exchange. Journal of Vacation Marketing, 14(2), 99-110.

Schmidt, S., Cantallops, A. S. \& dos Santos, C. P. (2008). The characteristics of hotel websites and their implications for website effectiveness. International Journal of Hospitality Management, 27(4), 504-516.

Thompson, J. \& Richardson, B. (1996). Strategic and competitive success: towards a model of the comprehensively competent organization. Management Decision, 34(2), 5-19.

Toh, R. S., Raven, P. \& DeKay, F. (2011). Selling Rooms: Hotels vs. Third-Party Websites. Cornell Hospitality Quarterly, 52(2), 181-189.

TravelCLICK. (2009). Retrieved October 1, 2010, from http://www.travelclick.net/informationcenter/bookings-by-channel.cfm

Tse, A. C. (2003). Disintermediation of travel agents in the hotel industry. International Journal of Hospitality Management, 22(4), 453-460.

Tso, A. \& Law, R. (2005). Analysing the online pricing practices of hotels in Hong Kong. International Journal of Hospitality Management, 24(2), 301-307. 
UST. (2012). La popolazione della Svizzera 2011. Retrieved March 2, 2013, from http://www.bfs.admin.ch/bfs/portal/it/index/news/publikationen.html?publicationID=4931

Vermeulen, I. E. \& Seegers, D. (2009). Tried and tested: The impact of online hotel reviews on consumer consideration. Tourism Management, 30(1), 123-127.

Wang, Y. \& Qualls, W. (2007). Towards a theoretical model of technology adoption in hospitality organizations. International Journal of Hospitality Management, 26(3), 560-573.

Werthner, H. \& Ricci, F. (2004). E-commerce and tourism. Commun. ACM, 47(12), 101-105.

Xiang, Z., Wöber, K. \& Fesenmaier, D. R. (2008). Representation of the Online Tourism Domain in Search Engines. Journal of Travel Research, 47(2), 137-150.

Ye, Q., Law, R. \& Gu, B. (2009). The impact of online user reviews on hotel room sales. International Journal of Hospitality Management, 28(1), 180-182.

Zafiropoulos, C., Vrana, V. \& Paschaloudis, D. (2006). The internet practices of hotel companies: an analysis from Greece. International Journal of Contemporary Hospitality Management, 18(2), 156-163.

Zhu, F. \& Zhang, X. (2006). The Influence of Online Consumer Reviews on the Demand for Experience Goods: The Case of Video Games. ICIS 2006 Proceedings. Retrieved from http://aisel.aisnet.org/icis2006/25

Zhu, F. \& Zhang, X. (Michael). (2010). Impact of Online Consumer Reviews on Sales: The Moderating Role of Product and Consumer Characteristics. Journal of Marketing, 74(2), 133 148. 
[TABLE 1]

Table 1: Descriptive Statistics

\begin{tabular}{|c|c|c|c|c|}
\hline Variable & $\begin{array}{l}\text { Mean } \\
\text { (or \%) }\end{array}$ & SD & Min & $\operatorname{Max}$ \\
\hline \multicolumn{5}{|l|}{ Hotel-Specific Characteristics } \\
\hline Room capacity $^{(*)}$ & 43.16 & 52.88 & 1 & 430 \\
\hline Category (zero-two stars) & $0.31 \%$ & & & \\
\hline Category (three stars) & $0.45 \%$ & & & \\
\hline Category (four-five stars) & $0.25 \%$ & & & \\
\hline \multicolumn{5}{|c|}{ Importance of Specific Factors in Selection of an Online Platform ${ }^{(a)}$} \\
\hline Commission & 2.88 & 1.10 & 0 & 4 \\
\hline Importance of the platform & 3.52 & 0.95 & 0 & 4 \\
\hline Effectiveness of marketing and resources & 3.37 & 0.83 & 1 & 4 \\
\hline Popularity & 3.54 & 0.85 & 0 & 4 \\
\hline Information on the hotel & 3.33 & 0.93 & 0 & 4 \\
\hline Data management (front office interface) & 3.18 & 1.07 & 0 & 4 \\
\hline Functionality of booking technology & 3.20 & 1.10 & 0 & 4 \\
\hline Convenience for the customer & 2.96 & 1.14 & 0 & 4 \\
\hline \multicolumn{5}{|l|}{ Importance for Online Sales ${ }^{(a)}$} \\
\hline Booking.com for sales & 2.91 & 1.53 & 0 & 4 \\
\hline Social media for sales & 2.49 & 1.27 & 0 & 4 \\
\hline \multicolumn{5}{|l|}{ Online Management } \\
\hline Channel manager & $0.28 \%$ & & & \\
\hline Booking engine on hotel website & $0.53 \%$ & & & \\
\hline \multicolumn{5}{|l|}{ Full time Personnel Dedicated to: } \\
\hline Website management ${ }^{(* *)}$ & 0.81 & 1.01 & 0 & 5 \\
\hline Online sale management & 0.82 & 0.66 & 0 & 3 \\
\hline
\end{tabular}

Note: ${ }^{(*)}$ Two cases missing; ${ }^{(* *)}$ Three cases missing; ${ }^{(a)} 0=$ not at all important, $4=$ very important. 
[TABLE 2]

Table 2: Model Results

\begin{tabular}{|c|c|c|c|c|}
\hline & \multicolumn{4}{|c|}{ Importance for Online Sales } \\
\hline & \multicolumn{2}{|c|}{ SocialMedia } & \multicolumn{2}{|c|}{ Booking.com } \\
\hline & Coeff. & (t-ratio) & Coeff. & (t-ratio) \\
\hline Constant & -2.6519 & $(-2.58)^{\mathrm{a}}$ & -2.8546 & $(-2.29)^{\mathrm{b}}$ \\
\hline \multicolumn{5}{|l|}{ Importance for Online Sales } \\
\hline Booking.com & 0.6922 & $(4.78)^{\mathrm{a}}$ & & \\
\hline Social media & & & 0.8738 & $(3.94)^{2}$ \\
\hline \multicolumn{5}{|c|}{ Importance of Specific Factors in Selection of an Online Platform } \\
\hline Commission & - & - & -0.4140 & $(-1.69)^{\mathrm{c}}$ \\
\hline Importance of the platform & - & - & 0.5856 & $(1.90)^{\mathrm{C}}$ \\
\hline Effectiveness of marketing and resources & 0.3965 & $(1.59)^{*}$ & -0.6886 & $(-1.79)^{\mathrm{c}}$ \\
\hline Popularity & - & - & 0.8313 & $(2.33)^{\mathrm{b}}$ \\
\hline Information on the hotel & - & - & - & - \\
\hline Data management (front-office interface) & - & - & - & - \\
\hline Functionality of booking technology & 0.5674 & $(2.76)^{\mathrm{a}}$ & - & - \\
\hline Convenience for the customer & - & - & - & - \\
\hline \multicolumn{5}{|l|}{ Online Management } \\
\hline Channel manager & - & - & - & - \\
\hline Booking engine on the hotel website & 1.4210 & $(3.36)^{\mathrm{a}}$ & - & - \\
\hline \multicolumn{5}{|l|}{ Full-Time Personnel Dedicated to } \\
\hline Website management & 0.4733 & $(1.72)^{\mathrm{c}}$ & - & - \\
\hline Online sales management & -0.9000 & $(-2.08)^{b}$ & 0.7856 & $(1.96)^{b}$ \\
\hline \multicolumn{5}{|l|}{ Hotel-Specific Characteristics } \\
\hline Category (three stars) & - & - & 1.4300 & $(2.66)^{2}$ \\
\hline Category (four to five stars) & - & - & 0.1902 & $(0.33)$ \\
\hline Room capacity & 0.0083 & $(1.45)^{* *}$ & - & - \\
\hline \multicolumn{5}{|c|}{ Threshold Parameters } \\
\hline $\mathrm{Mu}(1)$ & 1.1913 & $(4.26)^{\mathrm{a}}$ & - & - \\
\hline $\mathrm{Mu}(2)$ & 3.2247 & $(12.60)^{\mathrm{a}}$ & 0.6512 & $(3.18)^{2}$ \\
\hline $\mathrm{Mu}(3)$ & 4.8501 & $(15.20)^{\mathrm{a}}$ & 1.8720 & $(6.15)^{a}$ \\
\hline \multicolumn{5}{|c|}{ Model Fits } \\
\hline Number of observations $\left(N_{T o t}\right)$ & \multicolumn{2}{|c|}{92} & \multicolumn{2}{|c|}{97} \\
\hline $\ln L_{\text {Restricted }}$ & \multicolumn{2}{|c|}{-139.156} & \multicolumn{2}{|c|}{-110.611} \\
\hline $\ln \mathrm{L}_{\text {Model }}$ & \multicolumn{2}{|c|}{-110.447} & \multicolumn{2}{|c|}{-85.757} \\
\hline McFadden pseudo $\mathrm{R}^{2}$ & \multicolumn{2}{|c|}{0.206} & \multicolumn{2}{|c|}{0.225} \\
\hline Count $\mathrm{R}^{2}$ & \multicolumn{2}{|c|}{0.500} & \multicolumn{2}{|c|}{0.650} \\
\hline Adjusted Count $\mathrm{R}^{2}$ & \multicolumn{2}{|c|}{0.303} & \multicolumn{2}{|c|}{0.210} \\
\hline
\end{tabular}

Note: $a=$ prob $<1 \%$; $=$ prob $<5 \%$; $c=$ prob $<10 \%$; ${ }^{*}$ significant at $11 \%$; ${ }^{* *}$ significant at $15 \%$. 
[TABLE 3]

Table 3: Marginal Effects

\begin{tabular}{|c|c|c|}
\hline & \multicolumn{2}{|c|}{ Importance for Online Sales } \\
\hline & SocialMedia & Booking.com \\
\hline & $y_{j}=4$ & $y_{j}=4$ \\
\hline \multicolumn{3}{|l|}{ Importance for Online Sales } \\
\hline Booking.com & 0.102 & \\
\hline Social media & & 0.214 \\
\hline \multicolumn{3}{|c|}{ Importance of Specific Factors in Selection of an Online Platform } \\
\hline Commission & - & -0.102 \\
\hline Importance of the platform & - & 0.144 \\
\hline Effectiveness of marketing and resources & 0.058 & -0.169 \\
\hline Popularity & - & 0.204 \\
\hline Functionality of booking technology & 0.083 & - \\
\hline \multicolumn{3}{|l|}{ Online Management } \\
\hline Booking engine on hotel website & 0.201 & - \\
\hline \multicolumn{3}{|l|}{ Full-Time Personnel Dedicated to } \\
\hline Website management & 0.070 & - \\
\hline Online sales management & -0.132 & 0.193 \\
\hline \multicolumn{3}{|l|}{ Hotel-Specific Characteristics } \\
\hline Category (three stars) & - & 0.334 \\
\hline Room capacity & 0.001 & - \\
\hline
\end{tabular}

